\title{
SER MÃE E PROFESSORA: OS DESAFIOS DAS MULHERES NO PERCURSO DA CARREIRA DOCENTE NO SÉCULO XX
}

\author{
Luzia Aparecida Silva ${ }^{1}$; Irlana Jane Menas da Silva \\ 1. Bolsista PIBIC/PROBIC-UEFS, Graduanda em Licenciatura em Pedagogia, Universidade Estadual de Feira de Santana, e- \\ mail: lumarifsa@gmail.com \\ 2. Orientadora, Departamento de Educação, Universidade Estadual de Feira de Santana, e-mail: \\ irlanamenas@hotmail.com
}

PALAVRAS-CHAVE: desafios; carreira docente; dona de casa.

\section{INTRODUÇÃO}

O estudo da História da Educação nos ajuda a refletir sobre alguns processos que estão postos no nosso cotidiano. Desse modo, podemos compreender o espaço escolar como um território que inicialmente pertenciam aos homens no que tange ao direito de estudar quanto ao de exercer a profissão docente. Contudo, no final do século XIX para o início do século XX a mulher começa a assumir este espaço de profissional docente, porém, a ela ainda caberia $\mathrm{o}$ cuidado com os filhos, da casa e do esposo. Neste sentido, este trabalho científico é resultado de uma pesquisa de Iniciação Científica e teve como agência financiadora a PROBIC/UEFS, sendo desenvolvida no Grupo de Estudos e Pesquisas em História, Educação e Gênero (GEPHEG), em Feira de Santana, Bahia. A pesquisa surgiu a partir de questionamentos, sobre como essas mulheres que eram professoras e mães conciliavam a diversidade de papéis atribuídos a elas, visto que, nesse período começavam a serem vistas fora do espaço doméstico, como trabalhadoras remuneradas. Nesse trabalho, propusemos como objetivos, compreender os desafios enfrentados pelas mulheres que eram professoras e mães no século $\mathrm{XX}$, bem como, conhecer as estratégias que elas utilizavam para conciliar suas atividades domésticas com a função docente. Utilizamos como referência os estudos de Chamon (2005), Fidalgo (2003), Louro (2017), Uchôa (2016), dentre outros autores/as que abordam sobre a temática aqui apresentada.

\section{MATERIAL E MÉTODOS OU METODOLOGIA (ou equivalente)}

Esta pesquisa está pautada na abordagem qualitativa (Silveira \& Córdova, 2009, p. 32), tivemos como sujeitos professoras das séries iniciais que foram formadas pela Escola Normal de Feira de Santana, Bahia, no século XX, as quais eram casadas e que, durante o exercício da profissão docente, tiveram que conciliar, entre outras demandas, a maternidade e a docência. A coleta das informações foi realizada através de entrevistas semiestruturadas (Minayo, 2016, p. 59), durante o período de 06 a 26 de fevereiro de 2018, e aconteceram no próprio lar dos sujeitos da pesquisa, mediante agendamento prévio no qual se obteve autorização para que os relatos fossem gravados. Para isto, as entrevistadas assinaram um Termo de Consentimento Livre e Esclarecido, elaborado em conjunto com a orientadora deste projeto. Durante todo o processo, foi esclarecido para as entrevistadas que o sigilo de suas identidades seria mantido e, caso houvesse algum tipo de situação e/ou questões desconfortáveis, poderiam desistir da entrevista a qualquer momento, sendo respeitada a sua decisão. Assim sendo, conseguimos realizar entrevistas com três professoras, que designaremos como P1, P2 e P3, com idade de 76 anos (seis filhos), 80 anos (cinco filhos) e 78 anos (um filho) respectivamente, sendo estas formadas no período entre 1962 a 1973. A análise dos dados foi elaborada a partir da abordagem de Bardin (2011), através de categorias que evidenciam as falas das professoras entrevistadas, abrangendo a possibilidade de interpretação destes dados mediante o conteúdo proferido. 


\section{RESULTADOS E/OU DISCUSSÃO (ou Análise e discussão dos resultados)}

A partir das entrevistas com as professoras percebeu-se que a escolha pela profissão decorreu pelos seguintes fatores: devido ao afeto por crianças, como nos diz P1: "Olha, eu escolhi ser professora porque eu gostava muito de trabalhar com crianças [...]"; por ser a única opção para as mulheres na época como aponta a P2: "Na época em que eu estudava, pra mulher era a única opção. Assim na minha classe média, a única opção era ser professora"; por influência das amigas ou pelo status/valorização social que a profissão proporcionava no século $\mathrm{XX}$, no período mencionado, como relata a P3: "Eu escolhi ser professora mais por influência das colegas [...] Era valorizado na época. E a gente tinha orgulho, sabe? Que tinha de tá estudando pra professora. Ave Maria! (risos)".

Desse modo, tanto na análise das falas da P1, P2, e P3, a escolha da profissão docente é interpelada pelos vários discursos acerca da ideia de ser mulher, o que inclui a concepção de ser professora como trabalho feminino por excelência (Almeida, 2014, p. 85). O prestígio social e o status advindo da profissão, embora se mostre relevante para a escolha de ser professora, esconde-se atrás de uma condição estabelecida para essas mulheres, e que não pode "transpor os limites do socialmente adequado". Estes limites estão relacionados à "capacidade" da mulher para o trabalho com crianças, tendo em vista a crença daquele período de que estas eram mais "afeitas ao sacrifício e ao amor desinteressado" (Cruz, 2004, p. 158), bem como, as suas características "inatas" como o cuidado, a sensibilidade e a doçura (Chamon, 2005, p. 68-69).

Nossas entrevistadas relatam sobre os diversos enfrentamentos pelos quais tiveram que passar, dentre eles a relação com o esposo que ainda não estava habituado a vê-la trabalhando fora do lar, como aponta a P1: "O marido, de modo particular sempre tinha aquela visão de que a mulher era dentro de casa. Que a mulher tem os trabalhos de casa e é pra servir o marido e é essa coisa. Sempre a gente ouvia isso. [...]", além do preconceito ou discriminação social por ser mulher trabalhadora, como relata a P2: “[...] Antigamente fazia assim... uma certa discriminação aquela mulher que saía para trabalhar. Achavam que a mulher saía pra trabalhar, deixava a casa desleixada, que não tinha cuidado com as atividades domésticas, tinha uma certa rejeição", bem como, a dupla jornada de trabalho referente aos afazeres domésticos e o cuidado com os filhos, apontado por a P3, que, apesar de não considerar ter passado tanta dificulades, traz em sua fala alguns aspectos relacionados ao que se esperava da mãe trabalhadora naquele período.

P3: Eu não senti dificuldade, não. Porque no tempo que eu ganhava neném, a gente tinha quatro meses de licença. Então esses quatro meses dava assim, pra resolver muita coisa. Até arranjar assim, por exemplo, ainda mais assim que eu trabalhava no Assis, morava aqui, tá. Então pra mim não era longe. Aí quando chegava, cuidava dele. Antes de sair já deixava tudo que tinha de deixar já arrumado. Aí, ele ficava uma parte com F. (o pai) também. Aí nunca tive dificuldade não. Pra mim foi tudo mais tranquilo.

Através dos relatos podemos perceber que as três entrevistadas, além do preconceito, sofriam também com a demanda de atividades que lhes eram atribuídas. A crença de que eram elas as responsáveis pelo cuidado da casa, dos filhos e do marido, pode ser entendida como um ponto que contribuiu de forma não muito positiva durante a realização de suas jornadas. Estas mulheres desafiam uma ordem social estabelecida e buscam pelo protagonismo de suas próprias histórias.

Para que fosse possível conciliar os diferentes papéis atribuídos às mulheres da nossa entrevista, o planejamento das tarefas mostrou-se como uma das estratégias fundamentais. Outras estratégias utilizadas por elas vão desde o auxílio dos filhos e dos familiares na execução das atividades diárias à contratação de empregadas domésticas. Nesse sentido, o 
apoio recebido pelas entrevistadas, seja de uma empregada doméstica ou de algum de seus familiares, foi fundamental para a realização das tarefas diárias e para o cumprimento de seus planejamentos como docente. Deste modo, podemos inferir que, caso estas mulheres não tivessem essa rede de apoio, seriam obrigadas a abdicar do trabalho remunerado, voltando-se para o cuidado exclusivo do lar e dos filhos (Uchôa, 2016, p. 93).

A educação para o magistério, enquanto profissão feminina compreendeu, por muito tempo, em um trabalho voltado para a missão de ensinar, de educar gerações, bem como a execução de atividades dentro do lar. Assim, perguntamos às entrevistadas a respeito da profissão de professora e a influência no cuidado com seus/suas filhos(as) e com o lar. Para a P1, o magistério proporcionou o aprendizado que ultrapassou os limites da sala de aula, atingindo as esferas do lar e da própria saúde. Ser professora, de acordo com a fala de P1, pode ser entendido como uma base para lidar com acontecimentos que são exigidos na vida de mãe. Nesse sentido, a P2 concorda com essa influência. Para ela, o fato de ter se formado no magistério e ter exercido a profissão ajudou, antes de tudo, na formação dos seus filhos. Entretanto, para P3, pouca influência pode ser observada. A entrevistada comenta que ao ter um filho muitas sugestões são dadas por parte de amigas e até mesmo familiares, mas, para ela, o que importava mesmo eram as experiências diárias.

A influência do magistério nos trabalhos do lar, bem como no cuidado das mães para com seus filhos é algo que podemos perceber nos estudos realizados. Às mães cabia o trabalho com a disciplina dos filhos no lar, ensinando-lhes normas e costumes da época (Chamon, 2005, p. 124). Deste modo, as atividades desempenhadas por essas mulheres enquanto mães e enquanto professoras pouco se delimitava e, em um processo dialógico, o que se aprendia no lar era levado para sala de aula, bem como acontecia no modo inverso.

\section{CONSIDERAÇÕES FINAIS (ou Conclusão)}

Com esta pesquisa, foi possível perceber alguns desafios destas personagens no que diz respeito à relação Mulher, Mãe e Professora no século XX, como a inflexibilidade do marido quanto à ideia de que elas pudessem inserir-se em uma profissão, a carga excessiva de atribuições a serem realizadas, e o próprio fato de ser mulher em uma sociedade na qual ainda podia se notar alguns discursos contrários à sua autonomia e liberdade.

Nota-se que as estratégias de planejamento e organização foram fundamentais para que suas atividades pudessem ser desenvolvidas além de, em alguns casos, o apoio de familiares e empregadas. Podemos notar, também, as diversas influências para a escolha da profissão docente, como a influência do pensamento do ser professora como "feminino por excelência", que acabou por levar algumas mulheres à escolha do magistério. Embora os motivos para a escolha da profissão sejam diversos, a profissão de magistério, para estas mulheres, mostrouse, para além do apoio adquirido no trabalho com o lar e com os filhos, como uma fonte de autonomia e liberdade, uma forma de ser e estar no mundo.

Diante de debates como estes, que abordam a questão da mulher e seus enfrentamentos sociais, observa-se a importância deste trabalho como forma de conscientização e entendimento dos seus diversos papéis (historicamente construídos) na sociedade, buscando uma melhoria para o desenvolvimento e valorização dos mesmos bem como a visibilidade da figura da Mulher no meio social e cultural. Deste modo, a educação faz-se necessária no processo de tomada de consciência e para uma possível mudança de paradigmas, pois, como aponta Paulo Freire (1987, p. 87), "Educação não transforma o mundo. Educação muda pessoas. Pessoas transformam o mundo".

Por fim, agradecemos às professoras pela colaboração nessa pesquisa que nos ajudou a compreender sobre as modificações e permanências de pensamentos a respeito do trabalho feminino, sobretudo da mulher que é mãe. Além de nos alertar sobre como foram precursoras históricas da desconstrução paradigmática de que a mulher deveria apenas ser mãe e dona do 
lar. Mulheres que nos ensinaram que neste trajeto entre a vida do lar e ser profissional resistiram a ideologia da feminização e construíram outras formas de se impor na sociedade.

\section{REFERÊNCIAS}

ALMEIDA, J. S. 2014. Mulheres na Educação: missão, vocação e destino? A feminização do magistério ao longo do século xx. In: SAVIANI, D. [et al.]. - 3. ed. - Campinas, SP: Autores Associados.

BARDIN, L. 2011. Análise de conteúdo. São Paulo: Edições 70.

CHAMON, M. 2005. Trajetória de Feminização do Magistério: Ambigüidades e conflitos. Belo Horizonte: Autêntica/FCH-FUMEC.

CRUZ, A. R. S. 2004. Mestras e Mestres para o sertão: criação e funcionamento da Escola Normal de Feira de Santana. Sitientibus, Feira de Santana, n. 31, p. 143-168, jul/dez.

FIDALGO, L. 2003. (Re) construir a maternidade numa perspectiva discursiva. Lisboa: Instituto Piaget.

FREIRE, P. 1987. Pedagogia do Oprimido. Rio de Janeiro: Paz e Terra.

MINAYO, M. C. S. 2016. Trabalho de campo: contexto de observação, interação e descoberta. In: MINAYO, M. C. S. (org.). Pesquisa Social: teoria, método e criatividade. Petrópolis, RJ. Vozes.

SILVEIRA, D. T; CÓRDOVA, F. P. 2009. A Pesquisa científica. In: GERHARDT, T. E; SILVEIRA, D. T. (Orgs.) Métodos de Pesquisa. UFRGS.

UCHÔA, M. R. 2016. Mulher e mercado de trabalho no Brasil: um estudo sobre igualdade efetiva baseado no modelo normativo Espanhol. São Paulo: LTr. 